\title{
Reduction in adverse effects of tracking devices on waterfowl requires better measuring and reporting
}

Thomas K. Lameris ${ }^{1,2,3^{*} \dagger}$ and Erik Kleyheeg ${ }^{3,4 \dagger}$

\begin{abstract}
Since the first studies in the mid-twentieth century, lightweight electronic tracking devices have been increasingly used to study waterfowl movements. With half a century of experience and growing sample sizes, it has become clear that the attachment of a tracking device can affect a bird's behaviour and fitness. This becomes problematic when it introduces uncertainty about whether the recorded data represent natural behaviour. Waterfowl may be particularly prone to tag effects, since many species are migratory and tracking devices can disrupt their waterproof plumage. The primary aim of this paper is to identify how tracking devices may affect waterfowl survival, migration and reproduction, and how better measuring and reporting of such effects can improve our understanding of the risks, providing a first step towards reducing their impact in future studies. We reviewed literature on electronic tracking of waterfowl to create an overview of currently recognized effects of harness-attached backpacks, implants, subcutaneous attachments and neck collars. Additionally, we analysed developments in the use of attachment methods, the weight of tracking devices relative to bird body mass, and the reporting rate of effects of tracking devices in 202 original tracking studies. We found that although the number of waterfowl tracking studies described in peer-reviewed literature has steeply increased over the past decades, reporting rates of potential effects have decreased from 65.0 to $26.5 \%$. Meanwhile, the mean weight of the tracking devices relative to the bird's body mass remained stable around 2.0\%. Major negative effects were reported in $17 \%$ of all studies and were found for all attachment methods. Overall, large differences exist in the occurrence and type of negative effects between species and studies, even if the same tracking methods were used. Inconsistent reporting of effects, lack of control groups to measure effects and incomplete descriptions of the methodology hamper the identification of factors contributing to these effects. To accomplish a reduction in adverse effects of tracking, it is necessary to improve the measuring and reporting of effects. We propose a framework for standardized reporting of methods in primary tracking studies and standardized protocols to measure effects of tracking devices on waterfowl.
\end{abstract}

Keywords: Anatidae, GPS logger, Radio transmitter, Satellite telemetry, Tracking studies, Waterfowl

\section{Background}

The development of lightweight electronic tracking devices, which can transmit or log global positions and are small enough to deploy on free-ranging wild birds, has unchained a revolution in ornithology [10]. Such devices enable tracking of birds during their entire

\footnotetext{
*Correspondence: thomaslameris@gmail.com

${ }^{\dagger}$ Thomas K. Lameris and Erik Kleyheeg contributed equally to this work

1 Department of Animal Ecology, Netherlands Institute of Ecology (NIOO),

PO Box 50, 6700 AB Wageningen, The Netherlands

Full list of author information is available at the end of the article
}

annual cycle, and assessing fine-scale movement behaviour and individual behavioural strategies, which is difficult or impossible using conventional marking methods (metal rings or colour bands), especially in long-distance migrants. The ability to remotely track bird movements with high resolution and accuracy, for example using current GPS transmitters (up to $5 \mathrm{~m}$ accuracy with a GPSfix every $3 \mathrm{~s}$ ), has greatly improved our understanding of their behaviour and ecology, with important implications for their conservation [41]. Due to their large body size, waterfowl (swans, geese and ducks) were already 
tracked regularly by radiotelemetry since the 1960s (e.g. [67]). When satellite transmitters were introduced in the 1980s, waterfowl were among the first birds to which attachment of the relatively large first models was considered acceptable (e.g. Trumpeter Swan Cygnus buccinator and Tundra Swan C. columbianus; $[56,81])$. As tracking devices became smaller, lighter and cheaper over the years [10], their use on birds has become a well-established tool in ornithology and an increasing number of species are being tracked in their natural habitat.

However, with an increasing availability of tracking devices and the corresponding increase in individual birds on which they are being deployed, the need to understand and reduce their potential detrimental effects on birds is ever pressing. A growing number of publications show that tracking may come with a cost for the animal, which becomes especially problematic when it affects the measured behaviour (reviewed in [4, 13, $55,84]$ ). Among the negative effects identified in these reviews are increased mortality, disturbed (migratory) behaviour and reduced reproductive success, eventually resulting in lower fitness. Study species, transmitter type and attachment method are the most obvious factors that may determine the effect on a bird and thus the success or failure of a tracking study. Taking these factors into account when designing a telemetry study is not only important for animal welfare, but will also ensure that the researcher can be confident that the observed behaviour (e.g. migration strategy) is not an artefact of the tracking method [86]. Thorough understanding of such factors, especially prior to studying an unfamiliar species or using unfamiliar materials or techniques, requires open communication among researchers and the exchange of positive as well as negative experiences from the field.

Important contributions to communication about effects of telemetry on birds have already appeared in scientific literature. A comprehensive meta-analysis of transmitter effects on a wide range of bird species by Barron et al. [4] has shown that tracking devices often (but some more than others, see [84]) affect the birds carrying them. Although the study did not find a direct effect on flight ability, some degree of negative effects were found for all other aspects of the birds' ecology and behaviour covered in this study. Energy expenditure and the probability to initiate nesting were most strongly affected, with obvious long-term fitness consequences. A metaanalysis of tagging effects on seabirds [82] found that despite a growing number of studies making use of tracking devices, still relatively few studies explicitly consider the possible adverse effects on their study species.

In this study, we focus on waterfowl (Anatidae), a group of birds that, despite their large body size, may be particularly prone to negative effects. Many waterfowl populations are migratory [18] and may be energetically constrained by carrying a tag [61]. Also, due to their aquatic habitat, the breaching of their waterproof plumage by device attachment may affect their thermoregulation $[3,49,60]$. Thanks to the long history of waterfowl tracking, much experience has been acquired by researchers in the field. Accordingly, papers discussing effects of loggers on several waterfowl species appear regularly in the literature, but considering the vast number of species tracked in the past decades, much more information on the extent of these effects must be available. Disclosing this information is essential to improve tracking methods and reduce the associated negative effects. The primary aim of this paper is to identify which problems are associated with different tracking methods and study species, and to set out directions towards the reduction in adverse effects in future studies, for which we deem improved measuring and reporting of these effects an important first step.

To this end, we reviewed the effects of tracking devices and attachment methods described in the literature and evaluated the occurrence and the reporting rate of effects in 202 primary tracking studies. Based on our findings, we propose a standardized format for reporting details of tracking methods used in waterfowl studies and give suggestions on how studies can be set up in order to improve detection of potential adverse effects of tracking devices on the study species. We hope that this will facilitate identification of the best practice methods for each combination of tracking method and waterfowl species. It is important to note that many of the field studies covered in this paper are based on pioneering work and it is explicitly not our intention to judge the practices of any individual researcher or research group. Rather, we hope to show here that these studies are now invaluable for evaluating how we can prevent problems in the future, which will ultimately lead to better science.

\section{Methods}

To evaluate the occurrence and reporting rates of potential effects, we performed a literature search in Web of Science and Google Scholar in December 2015 using the following search terms: (goose OR swan OR duck) AND (tracking OR GPS OR telemetry). We then included every study which was performed in the field (no captivity studies), and which used any attached electronic tracking device on waterfowl (thus including the full range of VHF-transmitters, PTT satellite transmitters, GPS-loggers, GPS-GSM transmitters and geolocators), attached using any method (thus including harness attachments, implants, neck collars, subcutaneous attachments and other methods). We complemented this list by reviewing cited and citing papers, finally 
resulting in a set of 202 relevant studies (see Additional file 1 for the complete list). Note that this list of waterfowl tracking studies is not fully comprehensive, but provides a representative sample for our evaluations. From this set of studies, we extracted basic details on tracking methods, study species, whether effects of tracking devices were reported and which effects were reported, when possible subdivided in effects on survival, migration and reproduction (Additional file 2). We considered a study to report effects if it compared the performance of birds equipped with tracking devices with a control group or with data extracted from earlier studies or other literature. For studies not reporting the body mass of the birds, we extracted the mean body mass for the relevant species and sex from the Handbook of Birds of the World [18]. If it was unclear which sex was tracked, we used the average weight of males and females taken together. By dividing the weight of the tracking device by the bird's body mass, we calculated the relative weight of the tracking device. For this calculation, we excluded studies that failed to report the weight of the tracking device or did not specify device weights used for different study species. For classification of the attachment methods, we followed the definition of Roshier and Asmus [72]: (1) harness backpack, (2) abdominally implanted, (3) anchored in skin and (4) neck collar. Their fifth category was "tags attached to feathers", but this method was used so rarely that we combined it into an "other methods" category, including also tags glued to other parts of the body, or to plastic leg rings. For the category of harness backpacks, we found only studies using wing loop attachments, none of the studies in our analysis used leg loop attachments.

\section{Waterfowl tracking: a brief history}

Our literature review revealed that the use of telemetry to remotely track waterfowl movements has increased rapidly over the past three decades (Fig. 1). So far, tracking devices have been deployed on waterfowl on all continents where waterfowl occur and included at least 54 species. Most tracking studies have been carried out in North America, making up 63\% of the papers in this review. Europe and Asia lag far behind, accounting for 18 and $12 \%$ of the tracking studies, respectively. Less than $5 \%$ of all tracking studies were carried out in Africa and Australia, and our literature search revealed only one study from South America. The first tracking studies were carried out in the 1960s (first studies in our review were carried out in the 1970s) and exclusively used radio transmitters. The first published study using platform transmitter terminals (PTTs, also known as satellite transmitters) appeared in 1986, and since then PTTs have become most used device in telemetry studies (Fig. 1a).

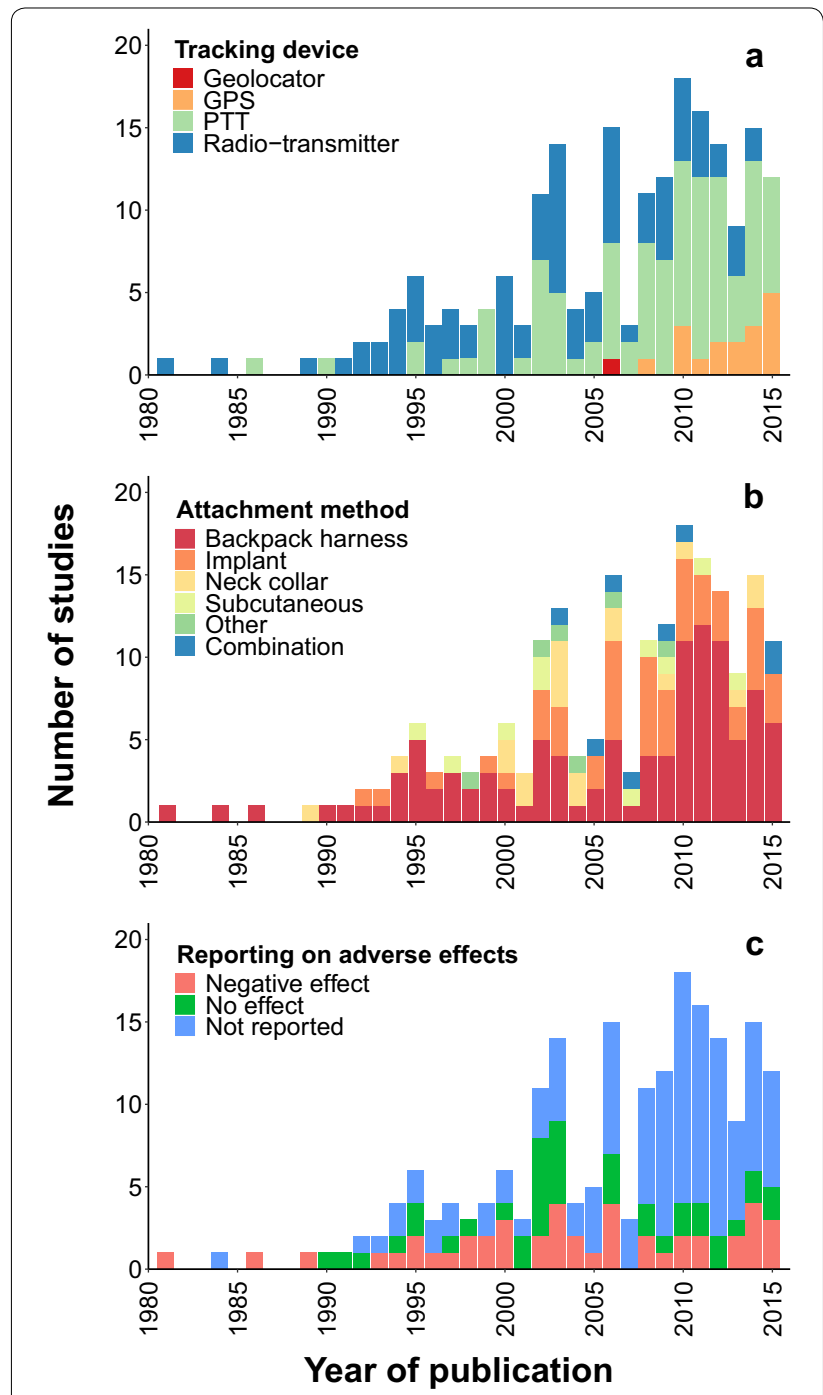

Fig. 1 Use of tracking devices, attachment methods and reporting rates over years of publication. Shown are number of studies per year of publication, split per tracking device type (a), attachment method (b) and whether the study reported on potential adverse effects (c)

However, since its first appearance in 2005, tracking devices using GPS have become increasingly popular in waterfowl telemetry and studies using this method already made up $42 \%$ of the publications in 2015 . It would be expected that studies using GPS devices will soon outnumber those using PTTs. Clearly, this field of research is still under rapid development.

Although tracking devices have changed over the years, the relative use of different attachment methods has remained largely unchanged (Fig. 1b). Backpack harnesses, the first method used to attach tracking devices, are still the most common method, followed by implantation. Neck collars were used more often in the early 
2000s, but have been used irregularly in the past 10 years. Apart from differences between attachment methods in adverse effects for waterfowl, the choice of attachment method should also depend on the research question of the researcher [44]. Harness-attached backpacks have the benefit of bringing the tracking device close the centre of gravity of the bird [44], while its placement on the back creates a large surface for charging of solar panels. Transmitter implantation in the abdominal cavity is sometimes preferred over the use of backpacks, especially in diving species, since this overcomes the problem of interruption of the waterproof plumage, as well as the problem of drag created by external devices during flying or diving. The main drawbacks of this method are that it does not allow the use of a solar panel to charge the batteries and that the procedure requires surgery by a specialized veterinarian. Mortality during or shortly after surgery can occur (e.g. [71]), and some studies using internal antennas also report a limited signal range of the transmitter as a major disadvantage [58]. Tracking devices can also be attached partly or completely subcutaneous. After making a small incision in the skin, either anchors attached to the tracking device (on one or two ends, e.g. [52]) or the complete tracking device can be placed under the skin (e.g. [45]), after which the incision can be closed by suture and/or glue. Depending on the scale and duration of the operation, birds can be briefly anesthetized (e.g. [12]). An important drawback of this attachment method is the high loss of subcutaneously attached transmitters, as was found in studies on Mallard Anas platyrhynchos (31 out of 49 transmitters lost, [73]), Northern Pintail Anas acuta (37 out of 82 lost, [26]) and Northern Shoveler Anas clypeata (20 out of 42 lost, Zimmer [88]). Neck collars with inscriptions are a common method to mark waterfowl, especially longer-necked species, for easy recognition in the field (e.g. $[16,55])$, but they can also be used as a basis for the attachment of tracking devices. As neck collars are exterior, they can be used for devices working on solar power.

Since the start of telemetry in birds, the mass of the tracking device relative to the bird's body mass has received much attention to make sure that the bird would not carry too much additional load. As a rule of thumb, devices weighing up to $5 \%$ of the body mass were considered acceptable and this was later reduced to a preferred $3 \%$ as tracking devices became smaller [42]. Already in the first telemetry studies in waterfowl, the relative mass of tracking devices was kept around 3\% of the bird's body mass. This was mainly due to the large species selected for these studies. Despite the decreasing weight of tracking devices over time (especially PTTs and GPS transmitters, Fig. 2a), the weight relative to the bird's body mass has not decreased much on average and remained stable

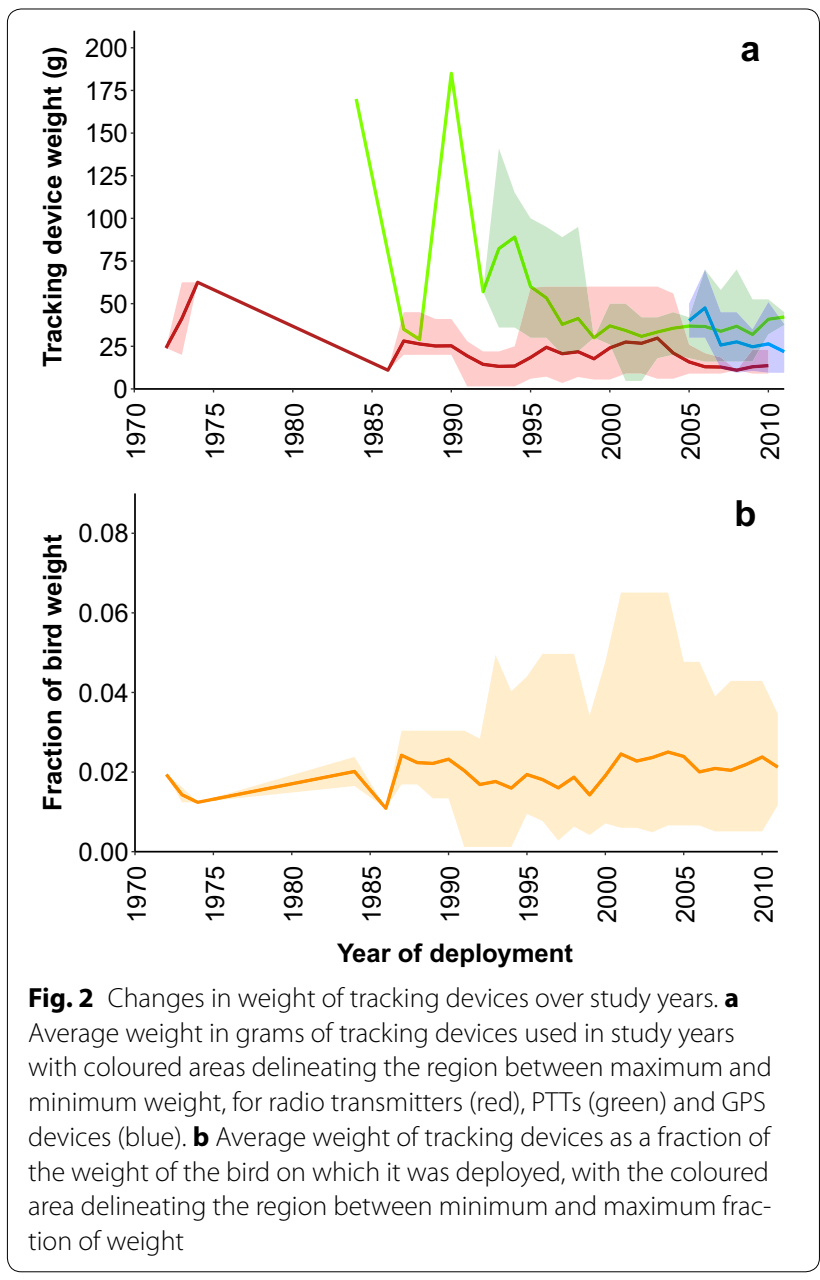

around $2 \%$, with occasional extremes within studies down to $0.1 \%$ and up to $6.5 \%$ of the bird's body mass (Fig. $2 \mathrm{~b}$ ). Part of the explanation for this is that smaller devices are used to track smaller waterfowl species. Radio transmitters have long been light enough to track small duck species, but only since a few years these species could be tracked using PTT or GPS devices, which provide much more data. The first waterfowl species lighter than $500 \mathrm{~g}$ to be tracked using modern tracking devices was the Eurasian Teal Anas crecca (mean weight $325 \mathrm{~g}$ ), tracked with 9.5 g GPS-PTTs in 2007 [59]. Another important explanation is that with the development of telemetry techniques, researchers opted for novel devices with more possibilities, rather than reducing device weight.

\section{Effects of tracking devices on waterfowl}

An important first step towards avoiding or reducing effects of deploying tracking devices on waterfowl is to know what can go wrong. We found that $17 \%$ of all original tracking studies (40\% of studies reporting potential effects) reported major, long-lasting negative effects of 
their tracking method. Here, we review the effects of different transmitter attachment techniques on waterfowl, including effects on survival, behaviour, migration and reproduction.

\section{Harness-attached backpack}

Harness attachment methods can have strong negative effects on survival. In one of the first studies using a harness as attachment method, all swans equipped with PTTs died before or during migration, which was attributed mostly to the weight of the $170 \mathrm{~g}$ devices [81]. Over the years, it has become clear that apart from the burden of carrying a heavy device, harness backpacks themselves are probably the main cause of deleterious effects on the birds carrying them. The main problematic features of harness backpacks are that they are relatively large external structures causing abrasion and drag, disrupt waterproof plumage and that the harness may be too loose or too tight, partly depending on the bird's body stores, which can vary greatly over the year especially in migrants [30, 43, 61, 62]. Effects on survival are most often detected by low return rates of tagged birds to breeding or staging sites compared to ring-marked individuals. The lowest return rate was reported in a study on female Barrow's Goldeneyes Bucephala islandica, with none of 16 tagged birds being recaptured in nest boxes during successive breeding seasons, relative to a background return rate of $66 \%$ [70]. Almost as poor was the $4 \%$ return rate of 62 Brent Geese Branta bernicla fitted with backpack transmitters to their Alaskan breeding site, compared to $57-83 \%$ return rates of colour-ringed individuals [83]. In a study in Saskatchewan, Canada, Mallards with harness transmitters had a return rate of $22.6 \%$ to their breeding grounds compared to $55 \%$ in individuals with an implanted transmitter [21]. Given the high site fidelity of these species, mortality is the most likely cause of these low return rates, although emigration cannot be fully ruled out. In contrast, other studies did not find any effects of harness attachments on survival. Survival rates over the course of the breeding season did not differ between Blue-winged Teals Anas discors with a harness backpack (61\% survival over 90 -day period) and individuals with an implanted transmitter (73\% survival over 90-day period), and although both groups could have suffered from reduced survival, the observed cases of mortality in this study seemed unrelated to the transmitter [29]. Winter survival of Northern Pintails did not differ between tagged and control individuals [26]. Cappelle et al. [14] reported loss of signal for nine out of 47 harness-attached satellite transmitters within 3 days after deployment for Garganey Anas querquedula (1 out of 18), Fulvous Duck Dendrocygna bicolour (2 out of 3) and Comb Duck Sarkidiornis melanotos (4 out of 20).
Signal loss may result from transmitter failure, and bird mortality was only confirmed in four of these cases. The authors speculated that this was related to stress induced by handling and capture. Other studies did not observe increased mortality shortly after release (e.g. [29]. Linking long-term effects of transmitters to bird mortality is often difficult in the field.

Besides occasionally reported to increase mortality, harnesses have been found to affect behaviour of tagged birds. Disturbed behaviour shortly after tag deployment is reported regularly, involving increased maintenance behaviour and reduced foraging [6, 30, 32, 62, 65, 70]. In some studies, these effects diminished over time ([32], E.K. pers. obs.), while they persisted in others $[30,62]$. In several cases, avoidance of water was observed, most likely due to loss of waterproofing capacity of the plumage caused by the harness, which may limit the access to food, reduce body condition and prompt (sometimes fatal) illness or starvation ([62, 30, 43, E.K. pers. obs.). On the longer term, feather and skin abrasion may occur, especially on the bird's back (underneath the transmitter) or at the pectoral muscle where the harness goes under the wing ([62], E.K. and T.L. pers. obs.). These abrasions could potentially lead to infection of the skin or altered behaviour due to thermoregulation problems. It should be noted that most physical effects can only be observed when birds are recaptured or when transmitter effects are tested in captivity. However, as most captivity studies (e.g. $[14,57])$ are relatively short term (1-2 months) and captive birds are often incapable of prolonged flight, it remains difficult to fully assess the negative effects of transmitters.

There is also evidence that harnesses increase the cost of migration. The shape and size of external backpacks (including the presence of an external antenna) can greatly affect the drag during flight. An increased drag, rather than the mass of the device, may reduce the migration distance and the reserves of the birds upon arrival, as shown by computer simulations by Pennycuick et al. [61]. This is supported by Bowlin et al. [9] who show that backpack attached geolocators on stuffed Common Swifts Apus apus increased drag and thus their flight ranges. Similarly, Hupp et al. [39] found that Northern Pintails equipped with $12-20 \mathrm{~g}$ satellite transmitters $[1-3 \%$ of the bird's body weight (BBW)] in East Asia build up a delay of 7.7 days per $1000 \mathrm{~km}$ during their migration compared to birds that were only ringed. Higher energetic costs during flight are given as a likely explanation. In a recent study on Barnacle Geese Branta leucopsis, timing of migration of individuals equipped with GPSloggers (35 g, 2\% BBW) was slightly delayed in the first stretch of northward migration when compared to individuals that carried lightweight $(1 \mathrm{~g})$ geolocators on their 
colour rings (Lameris et al. unpublished data). Blouin et al. [6] speculate that the tag or harness may have contributed to the fact that none of the six satellite-tagged Greater Snow Geese Chen caerulescens in their study completed migration successfully (tag weight: 100-140 g, $4-5 \% \mathrm{BBW})$. However, migration is not always affected, given the lack of any difference in timing of arrival at spring staging sites in Greenland White-fronted Geese equipped with dummy satellite transmitters (38-54 g, 1.5-2.0\% BBW; [32]) and timing of arrival and departure at a fall staging site in radio-tagged Brent Geese B. $b$. nigricans (radio transmitters of 26-25 g, 1.5-2.0\% BBW; [83]) compared to ringed-only individuals. It is likely that effects on energy expenditure or flight capacity are especially manifesting during the most energy-demanding migratory flights, as suggested also by the loss of three satellite-tagged Garganeys during the last stretch of their migratory flight across the Sahara (12 g satellite transmitters, 3\% BBW; [14]). During other activities, the negative effects on energy expenditure are probably less, as shown by a study of captive Brent Geese, where energy expenditure during activities other than flight was not affected by carrying a $35 \mathrm{~g}$ transmitter (2\% BBW; [76]).

If backpacks have a negative effect on migration and the condition of birds upon arrival on their breeding grounds, this may have carry-over effects on the breeding success, additional to potential direct effects of devices on breeding effort. Backpack attachments have been found to affect clutch size and timing and propensity of breeding. Pennycuick et al. [61] point out that lower energy height (a measure of energy reserves) in Barnacle Geese after spring migration may directly affect reproductive investment such as clutch size. Even though timing of migration in Brent Geese was not affected in a study by Ward and Flint [83], return rates from the wintering grounds to Alaska were dramatically low (1 out of 62 ) and the one female that had returned with a transmitter did not breed, in contrast to $90 \%$ breeding initiation in colour-ringed females. Pietz et al. [65] suggest that the significantly later onset of breeding and smaller clutches in radio-tagged Mallards compared to ringed individuals may have been related to the energetic consequences of a shifted time budget, with less feeding and more preening and maintenance behaviour due to the radio-tag. Accordingly, Rotella et al. [73] report that Mallards with harness transmitters nested 2 weeks later than birds with sutured-and-glued or implanted transmitters, although both groups could have been affected by the transmitter attachment. Barnacle Geese with GPS-loggers bred some days later than a control group carrying lightweight geolocators (Lamsiers et al. unpublished data). Bluewinged Teals captured and equipped with a backpack shortly before the breeding season failed to produce a nest twice as often as conspecifics with implanted devices [29]. Similarly, two Barrow's Goldeneyes equipped with a transmitter shortly before the onset of incubation abandoned the nest [70]. In contrast, the Blue-winged Teals as well as most of the Barrow's Goldeneyes captured and tagged during incubation did continue breeding $[29,70]$. Mallards tagged during late incubation did not have lower brood or duckling survival than mallards with implanted transmitters [21]. Finally, reproduction could be impaired by negative effects of harness-attached transmitters on pair bond, as suggested by a high proportion of unpaired tagged female Brent Geese ([83], Lameris et al. unpublished data).

In conclusion, although the weight of modern tracking devices is no longer the limiting factor for reducing negative effects of tracking devices, especially for larger birds, the device and the harness itself may still induce changes in survival and behaviour. These effects depend strongly on the device shape, the moment of attachment and probably also harness design, which can all be optimized to fit the study system. When aiming for long-term tracking of birds, devices need to be solar-charged, requiring external attachment. Unless the lifetime of tiny batteries will be greatly enhanced, which would enable less-invasive alternative attachment like attachment to leg rings, harnesses remain the only available attachment method for many species.

\section{Abdominal implants}

White et al. [84] argue, based on a meta-analysis, that detrimental effects of implanted devices on birds are less severe than for external devices. This is supported by several studies in waterfowl. Direct comparison between implants with internal antenna and (anchored) backpacks in wild female Mallards revealed that individuals with implants experienced significantly less negative impacts on survival and reproduction [60]. Dzus and Clark [21] compared the return rates of Mallards with harness-style backpacks and implants with internal antenna to their breeding areas and found a twice as high return rate for birds with an implant. However, in both studies the effect of implants is unclear since no untagged control group was included in the experimental design. A study with captive Blue-winged Teal, in which individuals with backpack, implant and no transmitter were compared, showed that birds with implants lost weight in the first week after surgery compared to both other groups, but had recovered by the second week. Blue-winged Teals with implants with internal antenna did not alter their behaviour, unlike birds with harness transmitters [30]. In the field, Blue-winged Teals with implanted transmitters with internal antenna had slightly, but not significantly, higher survival over the course of a breeding season than 
birds with harness transmitters and were more likely to initiate a nesting attempt [29].

An important impact of using implanted tags may be direct physical effects or mortality due to surgery. Korschgen et al. [46] describe the histological reaction of Mallards to implanted transmitters with external antennas and conclude that the mild to moderate air sac alterations they found did not cause any behavioural or physiological effects. Post-surgery survival of Spectacled Eiders Somateria fischeri equipped with implants with external antennas was found to be impacted by $\mathrm{pH}$ and haematocrit values of the blood prior to surgery. Birds with low $\mathrm{pH}$, or extremely low or high haematocrit had lower survival rates during the critical first five days after surgery [77]. Obtaining these values prior to surgery may help reduce the mortality rate. A paper describing the surgical procedure for implantation of transmitters in Canvasbacks Aythya valisineria reports no abnormal behaviour or increased mortality after implanting devices with internal antennas [58]. Hupp et al. [38] reported no post-surgery mortality in Lesser Canada Geese Branta canadensis parvipes tagged with radio transmitters with external antennas. Survival during their first year was similar to that of control individuals, although survival and return rates 2-4 years after tag deployment were slightly lower, potentially suggesting a subtle chronic tag effect. The feeding, maintenance and active behaviour of these tagged individuals were similar to that of unmarked individuals, and there was no sign that implantation affected the frequency of agonistic interactions [37]. The implantation of satellite transmitters with external antennas in Common Eiders Somateria mollissima during incubation led to the abandonment of 11 out of 12 nests in a Canadian study, but $30 \%$ of the tagged birds were observed nesting in the following years. Furthermore, the tagged birds spent more time preening than colourringed birds and suffered a $20 \%$ decrease in survival during the first year after surgery compared to the control group [25]. Limping was observed in some individuals, something which was also found by 1 out of the $6 \mathrm{Com}$ mon Eiders in the study of Latty et al. [49].

The lack of a harness and large external structures other than percutaneous antennas makes implanted transmitters the preferred tracking devices for diving ducks, such as eider species Somateria spec. and Harlequin Ducks Histrionicus histrionicus. Negative effects seem limited, but the difficulty with these seaduck species is that monitoring them post-surgery is often impossible. Brodeur et al. [11] were faced with signal loss of most satellite transmitters with internal antennas implanted in Harlequin Ducks in the months after deployment, but argue that resightings of several individuals up to 4 years later, combined with normal body temperature measurements before signal loss, indicated that this problem was caused by transmitter failure rather than bird mortality. Only one case of mortality was confirmed in this study and occurred within a few days after implantation, likely as a direct effect of surgery. An analysis of Harlequin Duck survival in Alaska revealed that recapture rates did not differ between birds with and without implants with external antennas, and only an average loss of body mass of $15 \mathrm{~g}$ was detected in the 2 weeks following the surgery [23]. Implanted transmitters can cause a change in diving behaviour as was shown in Common Eiders [48]. The descents and ascents of foraging dives were slower, and total dive durations were longer after implantation of transmitters with an external antenna than before. This may have been caused by muscle damage from the surgery, or by a biomechanical change affecting buoyancy or imbalance in these birds. The prolonged active phase of the dives may result in overall higher energy expenditure in tagged eiders, or force them to use different (e.g. shallower) habitats than untagged birds [48]. Latty et al. [49] also showed that implanted transmitters with external antennas affected bird health and physiology by a change in biomarkers up to 3.5 months after surgery. Although we did not find clear negative effects of implanted devices with external antennas compared with internal antennas, and no studies comparing the two, Hupp et al. [38] suggest that chronic low-grade infections from bacteria entering the body along the external antenna could potentially reduce long-term survival.

\section{Subcutaneous attachments}

Negative effects of transmitters placed under the skin are not often reported, which could be due to the low number of studies in our analysis that used this method. There is some evidence that subcutaneously anchored devices affect survival and reproduction of birds. In ducklings of Mallard and Gadwall Anas strepera, survival was lower for individuals equipped with subcutaneously anchored radio transmitters compared to an untagged control group [2, 47, 66]. The authors note entanglement as possible cause for lower survival, which was also reported for Harlequin Ducks [7]. Bakken et al. [3] found raised surface temperatures around transmitters attached with subcutaneous anchors in Mallard ducklings, but did not find differences in energetic costs for thermoregulation between marked and unmarked ducklings. The reduction in short-term survival rates of female Mallards of up to $23 \%$ in Paquette et al. [60], which was only significant in one out of five study sites, indicated that tags attached with subcutaneous anchors may sometimes affect adult birds. Other studies using subcutaneous implants found no effect on short-term survival of Lesser Scaups Aythya affinis [12], Surf Scoters Melanitta perspicillata and 
White-winged Scoters Melanitta deglandi [40] or on annual survival of Wood Ducks Aix sponsa [36]. Subcutaneous attachments have been found to negatively affect reproduction in some cases. Paquette et al. [60] found female Mallards with subcutaneously anchored backpacks to spend less time on egg laying and incubation and to initiate fewer nests. Enstipp et al. [24] found strongly altered behaviour in Long-tailed Ducks Clangula hyemalis with subcutaneous attachments, with increased preening behaviour and less time spent on the water, and two out of five individuals developed a bacterial infection at the site of attachment. Radio transmitters attached with prong and suture had no effect on reproduction in Wood Ducks [36].

\section{Neck collars}

Neck collars with tracking devices are often used in large, long-necked species, such as swans and geese. For these species, a neck collar can be more suitable than a backpack, as it diminishes the area over which abrasion and drag occurs, and lacks a harness which can be wrongly adjusted to the bird's shape and disrupts the plumage. However, as the weight of the tag is not positioned at the centre of gravity, this may become problematic for the bird when tags are relatively heavy [44]. In general, we found that neck collars used in studies are lighter (in mass relative to the bird's body mass) than harness-attached or implanted tags (backpack vs. neck collar: $t_{185,33}=8.26$, $p<0.001$; implant vs neck collar: $t_{105,33}=8.34, p<0.001$ ). Although several studies combined the use of neck collars and backpack attachments $[6,63,78]$, a proper comparison of effects is lacking. Blouin et al. [6] report that none of the Greater Snow Geese equipped with backpack transmitters reached the breeding grounds in 1993 and 1994 (due to signal loss, natural mortality or being shot), while four out of 11 birds equipped with neck collar transmitters did reach the breeding grounds in 1995. However, these transmitters were also lighter than the backpacks and direct comparison of attachment methods could not be made.

Neck collars with tracking devices can alter bird behaviour in similar ways as harness-attached backpacks, but this seems to be a short-term effect. In a captivity experiment, Kölzsch et al. [44] reported no difference in behaviour between Canada Geese equipped with neck collar transmitters or backpack transmitters, but both groups tended to spend more time preening and less time feeding. Increased preening behaviour was also observed in a study on captive Bewick's Swans C. columbianus bewickii with neck collar transmitters, but this effect had disappeared after 6 weeks [57]. Short-term effects on behaviour were also observed in the field. Snow Geese equipped with neck collar radio transmitters spent 2-3 times less time foraging than the control group in the season in which they were tagged, but this difference had disappeared in the following season [19]. Black Swans Cygnus atratus equipped with conventional neck collars were not affected in their behaviour compared to the control group [33].

Multiple studies report negative effects of neck collars on reproduction. Snow Geese equipped with neck collar transmitters showed a high rate of divorce from their original mate [19]. In subsequent breeding seasons, they delayed nest initiation and had smaller clutch sizes $[5,19]$. Also Canada Geese with neck collar transmitters experienced a lower nesting propensity and nested later than the control group [20]. Delayed laying can be the result of delayed or slowed down migration caused by drag of neck collars during flight [19], but such an effect has not yet been proven.

Shorter-necked species seem affected more by neck collars, although this has not specifically been studied. Older studies using neck collars with radio transmitters on various duck species (Wood Duck, Canvasback, Redhead Aythya americana) showed adverse effects on behaviour, survival and reproduction [31, 54, 79]. As can be expected for shorter-necked species, ducks with neck collars can get their lower mandible stuck in the collar, which leads to retarded behaviour and sometimes mortality [54, 79]. Not only ducks experience problems with neck collars, but negative effects have also been found for shorter-necked geese. The relatively short-necked Emperor Geese Chen canagica experienced lower survival, lower breeding propensity and laid one average one egg less when carrying a neck collar compared to a control group with leg rings [75]. Ross's Geese Chen rossii wearing neck collars were more vulnerable to being shot by hunters than birds marked with tarsal bands [15]. Feeding behaviour during winter was not affected in Brent Geese carrying narrow neck collars with radio transmitters [35], but negative effects of conventional neck collars have been found on courtship behaviour [1] and nesting success in this species [51].

A specific concern with the use of neck collars is that ice has been reported to accumulate on plastic collars under freezing temperatures (e.g. [27]). Formation of ice has in rare cases been shown to be fatal for birds (e.g. [87]), although other studies showed no effect on goose behaviour $[27,53]$. There are no reports of ice accumulation on other types of tracking devices.

\section{Other attachment methods}

The effects of other tag attachment methods, like gluing a device onto feathers or rings, have not often been tested in comparative studies. Enstipp et al. [24] compared tesasutured devices with subcutaneously anchored devices in 
Long-tailed Ducks and found that while birds with tesasutured devices recovered more rapidly from alterations of behaviour, tracking devices were lost after 26 days on average. Effects of other attachment methods were reported in original tracking studies. Survival and (re) nesting of Wood Ducks carrying a radio transmitter on a bib, a piece of fabric hanging from the neck on the chest, were lower than expected based on earlier studies, which may be related to the transmitter attachment [74]. We are unaware of other experiences with waterfowl carrying bibs. More conventional are devices mounted to the tail feathers. Guillemain et al. [34] glued and bound $3.5 \mathrm{~g}$ radio transmitters to the central rectrices of five dabbling ducks species. One of 21 individuals was found dead three days after logger deployment, but this was likely unrelated to tag attachment. Similarly, radio transmitters were glued and bound to the tail feathers of Mallard, Eurasian Teal and Northern Pintail in France by Legagneux et al. [50], but no details are provided about whether or not this affected the birds. Seven out of 20 tail-mounted transmitters of $17 \mathrm{~g}$ in Barnacle Geese were lost prematurely in a study by Phillips et al. [64], but no transmitter effects on the birds were reported. Reynolds [69] cut a small patch of feathers on the lower back of Laysan Teal Anas laysanensis to glue radio transmitters directly onto the skin and adhered them to uncut feathers with strips of tape. Also in this study, transmitter loss by detachment was frequent and the author did not report the presence or absence of effects on the birds. Miniature geolocators (light loggers) were attached to plastic leg rings of Barnacle Geese in a study by Eichhorn et al. [22], and no effects on nesting or survival were reported. A peculiar tag attachment method was tested in canvasbacks. After particularly bad experiences with harness backpacks,
[62] tested the attachment of radio transmitters on canvasback nasal saddles. Pilot studies on a limited number of canvasbacks in the laboratory and in the field were reported as promising and after a 6 -h adjustment period the birds behaved normally. However, we are not aware of follow-up studies by the author or any more recent study using this attachment method.

\section{Reporting of effects in primary tracking studies}

Our review has revealed the wide range of potential effects that are associated with different tracking device types and attachment methods, but has also shown that many effects are still poorly understood. Full understanding of how tracking devices affect the behaviour and survival of waterfowl can only be obtained when these effects are studied and reported. No two tracking studies are carried out under exactly the same circumstances following the exact same procedure; hence, every study can add knowledge on causes of effects and how they can be avoided. In order to identify how communication about tagging effects could be improved, we first analysed the reporting behaviour in current waterfowl tracking literature.

Eighty-four out of the 202 (42\%) primary tracking studies in this review (Additional file 1) reported the presence or absence of an effect of the tracking methodology (Table 1$)$. In only 18 of these 84 studies (21\%), this was based on a comparison of the tagged birds with a control group. Other studies based this on a comparison of tagged birds with data of the rest of the population (36 studies), a comparison with birds tagged using another tracking method (7 studies), observation of tagged birds (6 studies) or did not clarify (17 studies). Of the 84 studies that reported whether or not there was an effect, two

Table 1 Numbers and fractions (between brackets) of studies reporting effects of different types of tracking devices

\begin{tabular}{lcccrrr}
\hline & Backpack harness & Implant & Subcutaneous & Neck collar & Other & Total \\
\hline Reported & $45 / 112(0.40)$ & $25 / 59(0.42)$ & $6 / 14(0.43)$ & $9 / 23(0.39)$ & $3 / 6(0.50)$ & $84 / 202(0.42)$ \\
Control group & $8 / 45(0.18)$ & $5 / 25(0.2)$ & $1 / 6(0.17)$ & $4 / 9(0.44)$ & $0 / 3(0.0)$ & $18 / 84(0.21)$ \\
Negative & $22 / 45(0.49)$ & $9 / 25(0.36)$ & $1 / 6(0.17)$ & $6 / 9(0.67)$ & $1 / 3(0.33)$ & $39 / 84(0.46)$ \\
Minor negative & $4 / 22(0.18)$ & $1 / 9(0.11)$ & $0 / 1(0.00)$ & $0 / 6(0.00)$ & $0 / 1(0.00)$ & $5 / 39(0.13)$ \\
Major negative & $18 / 22(0.82)$ & $8 / 9(0.91)$ & $1 / 1(1.00)$ & $6 / 6(1.00)$ & $1 / 1(1.00)$ & $34 / 39(0.87)$ \\
Survival & $7 / 18(0.39)$ & $5 / 8(0.63)$ & $1 / 1(1.00)$ & $2 / 6(0.33)$ & $1 / 1(1.00)$ & $16 / 34(0.47)$ \\
Migration & $4 / 18(0.22)$ & $2 / 8(0.25)$ & $0 / 1(0.00)$ & $0 / 6(0.00)$ & $0(0.00)$ & $6 / 34(0.18)$ \\
Reproduction & $8 / 18(0.44)$ & $3 / 8(0.38)$ & $0 / 1(0.00)$ & $6 / 6(1.00)$ & $1 / 1(1.00)$ & $18 / 34(0.53)$
\end{tabular}

The "reported" category includes all studies reporting whether or not an effect was found. The "control group" category includes studies (as a fraction of the studies that report) that contrasted the potential negative effects of tagged birds with a control group. Studies reporting adverse effects ("negative") were split into studies which found only minor, short-term negative effects (only in the first weeks and not affecting survival, reproduction or migration) and studies which (also) found major, often long-term negative effects. The studies which found long-term negative effects were subdivided into studies reporting effects on survival, migration and reproduction if this information was provided. As in some studies negative effects were found in multiple of the above categories or were not specified, the total number of papers in these categories does not equal the number of studies that found negative effects. No studies reported positive effects of tracking devices 
mention that tag effects were hard to distinguish from other factors, and 43 studies specifically mention that there was no effect. In the other 39 out of 84 studies, the reported tagging effect was considered negative (no positive effects were reported), corresponding to $19.3 \%$ of the total of 202 studies. The number of studies that used control groups did not differ between studies that either did $(9 / 39 ; 23 \%)$ or did not find negative effects $(9 / 43$; $21 \%)$. When distinguishing between studies that found minor effects (such as short-term weight loss or behavioural changes lasting less than a few weeks) and major effects (directly impacting fitness via effects on survival, reproduction or migratory behaviour), we found that 34 out of the 39 studies reporting negative effects included major effects, which is $17 \%$ of the total of 202 studies. We broadly distinguished between effects on survival, reproduction and migration and found that only one of these 34 studies discussed all three components [38]. Most of the studies only mention effects on survival and/ or reproduction, while very few report effects on migration. Given the above described effects of transmitterinduced drag on the flight range of migrating waterfowl, this low report rate is unlikely due to a lack of effects but rather due to difficulties with detecting effects on migration. Since effects in wild birds can be difficult to detect in general, it is questionable whether studies explicitly claiming no adverse effects on their study species without the use of an untagged control group, used an appropriate study setup to detect such effects.

Interestingly, the reporting rate of potential effects on birds carrying tracking devices seems to have changed over time. It was rather high until the early 2000s $(65.0 \%$ of all studies reported the presence or absence of effects between 1981 and 2004), probably due to the novelty of using various techniques on birds. While more tracking studies were published in later years, this reporting rate dropped to $26.5 \%$ between 2005 and 2015. Of those studies in our review that did report potential effects, the fraction reporting negative effects remained stable over time around 51\% (Fig. 1c). The reporting rate did not seem to differ between attachment methods (Table 1). Studies using neck collars appear to find negative effects more often than studies using other attachment methods ( 6 out of 9 studies found negative effects, Table 1), yet these used birds that are most easily identified and observed in the field. Most of the effects of neck collars and backpack attachments were found on reproduction, while studies using implants more often found effects on survival. Studies using subcutaneous attachment rarely found negative effects, but note the high loss rate of the tags and the low number of studies that used this method.

\section{Towards reduction in adverse effects}

Our review demonstrates that attaching tracking devices to waterfowl may lead to adverse effects on survival, migration and/or reproduction in any species. Not all tracking studies report potential effects, so it is difficult to assess why and how often such effects occur. Moreover, many studies did not include a control group in the study design, which hampers the detection of potential effects. When studies explicitly report a lack of adverse effects in their study population, the question rises whether this could be due to low sample sizes, which decreases the detection probability, or due to inadequate measuring of potential effects. Some studies with very low sample sizes did find large effects, indicating that some effects can be quite dramatic, while on the other hand, some studies with large sample sizes, thus having a high probability of finding effects, did not find any (e.g. 185 birds in study by Esler et al. [23], 228 birds in Gaidet et al. [28] and 235 birds in Pietz et al. [65]). This would indicate that tracking waterfowl can be done without affecting the birds. By comparing the methodology of different studies and their reported presence or absence of effects, we should aim at identifying which tracking devices yield negative effects in which species, how they affect the bird, and under which circumstances these effects do and do not occur. This will be an important step towards further reduction in negative effects. In order to do so, it is essential that studies (1) report in detail on the methods used for tracking, and (2) measure and report the tracking device effects on the study species.

During our literature review, we found that details concerning the attachment of tracking devices were lacking in many studies. Most often, studies were unclear in reporting and differentiating the number of birds that were equipped with (sometimes different types of) tracking devices and the numbers eventually used in the data analysis (43 out of 202 studies). Also, the sex and age of the tagged birds were often not reported (19 out of 202 studies did not report the sex), and some studies did not report the weight of the tracking device (12 out of 202 studies). In order to compare the used methods and assess which method would be the best for a certain species, studies need to report the methods used for tracking birds to a certain detail. This information should be available in publications, but also in (open-access) databases where tracking data are stored, such as the Movebank Data Repository [85]. We propose a standard set of metadata to be reported for any tracking study on waterfowl:

1. Tracking device: type of positioning system (e.g. radio tracking, GPS, geolocation), type of transmitting system (e.g. satellite, GSM, bluetooth), producing company, dimensions and weight; 
2. Bird: (sub)species, sex, age (at least differentiation juvenile/adult), body mass, initial sample size of tagged birds, sample size of birds from which data was used in the analysis, whether a control group is used, marking method of control group, sample size of control group;

3. Capture method: location, date, period of the bird's annual cycle (e.g. breeding season, moulting period), catching method, handling time and other samples acquired;

4. Attachment method: type, material for attachment and combined weight of the attachment materials and the tracking device.

Measuring the possible adverse effects is essential when studying natural behaviour of birds using tracking devices. Even if adverse effects occur on behaviour that is not of direct interest for the study, these can still carry over in aspects of behaviour that are of interest. As an example, if birds fail to breed because they carry a tracking device, this will also have an effect on the timing of their autumn migration. When performing a tracking study, it is thus important to measure any possible adverse effects of the tracking device on the bird. Based on the studies used in this paper, as well as personal experience, we suggest that a first potential reduction in adverse effects can be managed by at least thoroughly reviewing the proposed methodology and measure them by adding a control group to the experimental design.

Reviewing earlier tracking studies on the same species is an essential first step before deploying tracking devices on a bird. Methodological studies, such as Roshier and Asmus [72] and Cumming and Ndlovu [17], can be very useful for this purpose. Studies on closely related species can be used, but subtle differences (also in environmental variables) can make species respond very differently to one attachment method. As an example, steel rings in a harness did not show wear in Barnacle Goose, but became rusty and likely broke when used in a harness in the closely related Brent Goose (A. Dokter, personal communication), as these geese spend more time in saline environments [80]. Experts in bird tracking often have experience with multiple species and can assist in evaluating what method would be suitable for which study species. To provide a first suggestion of what could be the most suitable tracking methods for waterfowl species included in our review, we have compiled an overview of how often negative effects were found for different attachment methods (Additional file 3).

When using a little known or unfamiliar attachment method or study species, it will prove very informative to perform a study in captivity before applying the tracking device on wild birds (e.g. [44, 57]). This way, the potential effects on time budgets (e.g. time feeding, preening) can be studied relatively easily, as well as shedding of the tracking device or the possibility that birds become entangled by the attachment method.

When designing a tracking study on wild birds, adding a control group which is treated in the same way as the tagged group but which lacks the tracking device makes it possible to measure differences in behaviour and survival (e.g. $[68,75])$. Marking birds in a control group with lightweight visual marks (metal and colour rings) is usually considered to be of little influence on the bird [13], while it enables later recognition in the field. Simple neck collars can probably be used for long-necked waterfowl without long-term effects, but have been found to affect reproduction and survival in some species $[15,51,68,75]$, and should thus be used as a control with caution. A control group should be treated in the same way as the tagged group in as many aspects as possible, including the method of capture, other samples taken (e.g. blood samples), attachment of visual marks (metal and colour rings) and potentially also handling time (although the attachment of the tracking device may increase handling time substantially). Adverse effects can then be measured by observing both the tagged and the control group in the field. Not all possible adverse effects can be measured easily, as it is often difficult to track birds in the control group equally well as birds with tracking devices. This is particularly true for measuring effects on migration. For larger birds, it is sometimes possible to equip a control group with lightweight $(<1 \mathrm{~g})$ geolocators on the colour rings, which can be used to measure migration variables such as moment of departure and arrival, and migration speed ([22], Lameris et al. unpublished). Yet, ring resightings and recoveries can also give useful estimates for comparison of some migration variables [39], such as the moment of arrival [8]. Observing birds after release can reveal differences in behaviour and short-term survival between the tagged group and the control group. One-year return rates (e.g. to the breeding colony) can give an indication of differences in annual survival, for which it is important to use the same observation method (i.e. visual observation) for both tagged and control groups. This will also enable estimation of the rate of transmitter failure, which helps to distinguish between signal loss and bird mortality. Effects on reproduction can be measured in multiple ways, e.g. by quantifying nesting propensity, nest initiation date, clutch size and hatching success. When possible, recapture of birds of the tagged group and the control group can give insights in physical effects, including body condition and physical damage as a result of the tracking device attachment [23]. Finally, it should be evaluated and discussed by the authors of original tracking studies to which degree the potential tag effects are indeed negative within the context of the species' life history and ecology. 


\section{Conclusions}

The primary aim of this study was to identify how attaching tracking devices on waterfowl may affect their survival, behaviour and reproduction, and explore how measuring and reporting of negative effects may provide directions towards reduction in these effects in future studies. Adverse effects on bird behaviour have been reported occasionally for all methods of attaching tracking devices, and there is not a single best method for all species. However, the occurrence and type of negative effects clearly differ for species and attachment methods, and based on earlier studies, it is often possible to determine a suitable method for single species (Additional file 3). If any negative effects are still to be expected, these should be outweighed by the scientific benefits of the study, as is usually legally mandatory and should be assessed by an animal welfare committee. In recent years, very few studies on waterfowl reported potential effects of tracking devices, while the fraction of studies in which negative effects were found has not decreased. This is a worrisome trend which is also reported for studies on seabirds [82]. When studying birds using tracking devices, it remains essential to determine whether their behaviour or fitness are affected, as this can greatly influence study results. We stress the importance of measuring effects of tracking device attachment on the behaviour and survival of birds to make sure that data on natural behaviour are collected. A promising way to reach broadly supported "best practice" methods for tracking studies is to combine expert knowledge of waterfowl researchers with comparative observations in the laboratory and in the field. We hope that the use of a standardized format for reporting details of tracking methods will improve the exchange of information, and we encourage researchers to measure effects of tracking devices on fitness and behaviour by adding control groups to their studies. These data should be reported in publications, but also in (open-access) databases where tracking data are stored for future use. This will lead to better science and pave the way towards a reduction in adverse effects of tracking devices on waterfowl in the future.

\section{Additional file}

Additional file 1. Complete list of all 202 papers used for meta-analysis. Additional file 2. Information extracted from studies, including categories when used.

Additional file 3. Number of studies that report effects and number of studies that find adverse effects ofattachment methods (underlined). Colours denote a "sensitivity" score for different species and attachment methods: green ( $0-33 \%$ of studies find negative effects), orange ( $34-66 \%$ of studies find negative effects)and red ( $67-100 \%$ of studies find negative effects). Note that in some cases this is based on only one studywhich reports (negative) effects.

\section{Authors' contributions}

$T L$ and EK collected and analysed the data from the literature, reviewed the literature on tag effects and wrote the manuscript together. Both authors read and approved the final manuscript.

\section{Author details}

${ }^{1}$ Department of Animal Ecology, Netherlands Institute of Ecology (NIOO), PO Box 50, 6700 AB Wageningen, The Netherlands. ${ }^{2}$ Theoretical and Computational Ecology, Institute for Biodiversity and Ecosystem Dynamics, University of Amsterdam, PO Box 94248, 1090 GE Amsterdam, The Netherlands. ${ }^{3}$ Dutch Centre for Avian Migration and Demography, Netherlands Institute of Ecology (NIOO), PO Box 50, 6700 AB Wageningen, The Netherlands. ${ }^{4}$ Ecology and Biodiversity Group, Institute of Environmental Biology, Utrecht University, Padualaan 8, 3584 CH Utrecht, The Netherlands.

\section{Competing interests}

The authors declare that they have no competing interests.

\section{Acknowledgements}

We thank Bart Nolet, Arie van Noordwijk, Rascha Nuijten, Andrea Kölzsch and three anonymous reviewers for their comments on an earlier version of this manuscript.

\section{Availability of data and material}

The datasets used and/or analysed during the current study are available from the corresponding author on reasonable request.

Consent for publication

Not applicable.

Ethics approval and consent to participate

Not applicable.

Funding

TL was funded by the Nederlandse Organisatie voor Wetenschappelijk Onderzoek, Grant NPP 866.13.010.

\section{Publisher's Note}

Springer Nature remains neutral with regard to jurisdictional claims in published maps and institutional affiliations.

Received: 4 April 2017 Accepted: 14 October 2017

Published online: 27 October 2017

References

1. Abraham KF, Ankney CD, Boyd H. Assortative mating by brant. Auk. 1993;100(201-20):3.

2. Amundson $\mathrm{CL}$, Arnold TW. Effects of radiotransmitters and plasticine bands on Mallard duckling survival. J Field Ornithol. 2010;81:310-6.

3. Bakken GS, Reynolds PS, Kenow KP, Korschgen CE, Boysen AF. Thermoregulatory effects of radiotelemetry transmitters on mallard ducklings. J Wild Manag. 2010;60:669-78.

4. Barron DG, Brawn JD, Weatherhead PJ. Meta-analysis of transmitter effects on avian behaviour and ecology. Methods Ecol Evol. 2010;1:180-7.

5. Bêty J, Gauthier G, Giroux JF. Body condition, migration, and timing of reproduction in snow geese: a test of the condition-dependent model of optimal clutch size. Am Nat. 2003;162:110-21.

6. Blouin F, Giroux JF, Ferron J, Gauthier G, Doucet GJ. The use of satellite telemetry to track greater snow geese. J Field Ornithol. 1999;70:87-199.

7. Bond J, Esler D. Bill entanglement in subcutaneously-anchored radio transmitters on Harlequin Ducks. Wilson J Ornithol. 2008;120:599-602.

8. Both C, Bijlsma RG, Ouwehand J. Repeatability in spring arrival dates in pied flycatchers varies among years and sexes. Ardea. 2016;104:3-21.

9. Bowlin MS, Henningson P, Muijres FT, Vleugels RH, Liechti F, Hedenström A. The effects of geolocator drag and weight on the flight ranges of small migrants. Methods Ecol Evol. 2010;1:398-402. 
10. Bridge ES, Thorup K, Bowlin MS, Chilson PB, Diehl RH, Fléron RW, et al. Technology on the move: recent and forthcoming innovations for tracking migratory birds. Bioscience. 2011;61:689-98.

11. Brodeur S, Savard JPL, Robert M, Titman RD, Fitzgerald G. Failure time and fate of Harlequin ducks implanted with satellite transmitters. Waterbirds. 2008;31:183-7.

12. Brook RW, Clark RG. Retention and effects of nasal markers and subcutaneously implanted radio transmitters on breeding female Lesser Scaup. J Field Ornithol. 2002;73:206-12.

13. Calvo B, Furness RW. A review of the use and the effects of marks and devices on birds. Ringing Migr. 1992;13:129-51.

14. Cappelle J, Iverson SA, Takekawa JY, Newman SH, Dodman T, Gaidet N. Implementing telemetry on new species in remote areas: recommendations from a large-scale satellite tracking study of African waterfowl. Ostrich. 2011;82:17-26.

15. Caswell JH, Alisauskas RT, Leafloor JO. Effect of neckband color on survival and recovery rates of Ross's geese. J Wildl Manag. 2012;76:1456-61.

16. Clausen KK, Madsen J. Effects of neckbands on body condition of migratory geese. J Ornithol. 2014;155:951-8.

17. Cumming GS, Ndlovu M. Satellite telemetry of Afrotropical ducks: methodological details and assessment of success rates. Afr Zool. 2011;46:425-34

18. Del Hoyo J, Elliott A, Sargatal J, Christie DA, De Juana E. Handbook of the birds of the world alive. Barcelona: Lynx Edicions; 2016.

19. Demers F, Giroux JF, Gauthier G, Bêty J. Effects of collar-attached transmitters on behaviour, pair bond and breeding success of snow geese Anser caerulescens atlanticus. Wild Biol. 2003;9:161-70.

20. Dieter CD, Anderson BJ. Reproductive success and brood movements of giant Canada geese in eastern South Dakota. Am Midl Nat. 2009;162:373-81.

21. Dzus EH, Clark RG. Effects of harness-style and abdominally implanted transmitters on survival and return rates of mallards. J Field Ornithol. 1996;67:549-57.

22. Eichhorn G, Afanasyev V, Drent RH, van der Jeugd HP. Spring stopover routines in Russian Barnacle Geese Branta leucopsis tracked by resightings and geolocation. Ardea. 2006;94:667-78.

23. Esler D, Mulcahy DM, Jarvis RL. Testing assumptions for unbiased estimation of survival of radiomarked harlequin ducks. J Wildl Manag. 2000;64:591-8.

24. Esntipp MR, Frost J, Hollmén TE, Andrews RD, Frost C. Two methods of radio transmitter attachment and their effects on the behavior and energetics of captive long-tailed ducks (Clangula hyemalis) during winter. Anim Biotelemetry. 2015;3:1.

25. Fast PL, Fast M, Mosbech A, Sonne C, Gilchrist HG, Descamps S. Effects of implanted satellite transmitters on behavior and survival of female common eiders. J Wildl Manag. 2011;75:1553-7.

26. Fleskes JP. Effects of backpack radiotags on female northern pintails wintering in California. Wildl Soc Bull. 2003;31:212-9.

27. Fox AD, Walsh AJ, Weegman MD, Bearhop S, Mitchell C. Spring ice formation on goose neck collars: effects on body condition and survival in Greenland white-fronted geese Anser albifrons flavirostris. Eur J Wild Res. 2014;60:831-4.

28. Gaidet N, Cappelle J, Takekawa JY, Prosser DJ, Iverson SA, Douglas DC, Perry WM, Mundkur T, Newman SH. Potential spread of highly pathogenic avian influenza H5N1 by wildfowl: dispersal ranges and rates determined from large-scale satellite telemetry. J Appl Ecol. 2010:47:1147-57

29. Garrettson PR, Rohwer FC. Reproductive effort and survival of wild bluewinged teal, Anas discors, with backpack harness and implant transmitters. Can Field Nat. 1998;112:212-6.

30. Garrettson PR, Rohwer FC, Moser EB. Effects of backpack and implanted radiotransmitters on captive blue-winged teal. J Wildl Manag. 2000;64:216-22

31. Gilmer DS, Ball IJ, Cowardin LM, Riechmann JH. Effects of radio packages on wild ducks. J Wildl Manag. 1974;38:243-52.

32. Gladher CM, Fox AD, Walsh AJ. Effects of fitting dummy satellite transmitters to Greenland white-fronted geese Anser albifrons flavirostris. Wildfowl. 1997:48:88-97.

33. Guay PJ, Mulder RA. Do neck-collars affect the behaviour and condition of Black Swans (Cygnus atratus)? Emu. 2009;109:248-51.
34. Guillemain M, Fritz H, Duncan P. The importance of protected areas as nocturnal feeding grounds for dabbling ducks wintering in western France. Biol Cons. 2002;103:183-98.

35. Hassall M, Riddington R, Helden A. Foraging behaviour of brent geese, Branta b. bernicla, on grasslands: effects of sward length and nitrogen content. Oecologia. 2001;127:97-104.

36. Hepp GR, FolkTH, Hartke KM. Effects of subcutaneous transmitters on reproduction, incubation behavior, and annual return rates of female Wood Ducks. Wild I Soc Bull. 2002:30:1208-14.

37. Hupp JW, Ruhl GA, Pearce JM, Mulcahy DM, Tomeo MA. Effects of implanted radio transmitters with percutaneous antennas on the behavior of Canada Geese. J Field Ornithol. 2003;74:250-6.

38. Hupp JW, Pearce JM, Mulcahy DM, Miller DA. Effects of abdominally implanted radiotransmitters with percutaneous antennas on migration, reproduction, and survival of Canada geese. J Wildl Manag. 2006:70:812-22.

39. Hupp JW, Kharitonov S, Yamaguchi NM, Ozaki K, Flint PL, Pearce JM, et al. Evidence that dorsally mounted satellite transmitters affect migration chronology of Northern Pintails. J Ornithol. 2015;156:977-89.

40. Iverson SA, Boyd WS, Esler D, Mulcahy DM, Bowman TD. Comparison of the effects and performance of four types of radiotransmitters for use with scoters. Wildl Soc Bull. 2006:34:656-63.

41. Kays R, Crofoot MC, JetzW, Wikelski M. Terrestrial animal tracking as an eye on life and planet. Science. 2015;348:aaa2478.

42. Kenward RE. A manual for wildlife radio tagging. London: Academic Press; 2001

43. Kesler DC, Raedeke AH, Foggia JR, Beatty WS, Webb EB, Humburg DD, Naylor LW. Effects of satellite transmitters on captive and wild mallards. Wildl Soc Bull. 2014;38:557-65.

44. Kölzsch A, Neefjes M, Barkway J, Müskens GJ, Langevelde F, de Boer WF, et al. Neckband or backpack? Differences in tag design and their effects on GPS/accelerometer tracking results in large waterbirds. Anim Biotelemetry. 2016:4:13.

45. Korschgen CE, Kenow KP, Green WL, Samuel MD, Sileo L. Technique for implanting radio transmitters subcutaneously in day-old ducklings. J Field Ornithol. 1996;67:392-7.

46. Korschgen CE, Kenow KP, Gendron-Fitzpatrick A, Green WL, Gein FJ. Implanting intra-abdominal radiotransmitters with external whip antennas in ducks. J Wildl Manag. 1996;60:132-7.

47. Krapu GL, Pietz PJ, Brandt DA, Cox RR Jr. Does presence of permanent fresh water affect recruitment in prairie-nesting dabbling ducks? J Wildl Manag. 2004:68:332-41.

48. Latty CJ, Hollmén TE, Petersen MR, Powell AN, Andrews RD. Abdominally implanted transmitters with percutaneous antennas affect the dive performance of common eiders. Condor. 2010;112:314-22.

49. Latty CJ, Hollmén TE, Petersen MR, Powell AN, Andrews RD. Biochemical and clinical responses of common eiders to implanted satellite transmitters. Condor. 2016;118:489-501.

50. Legagneux P, Blaize C, Latraube F, Gauthier J, Bretagnolle V. Variation in home-range size and movements of wintering dabbling ducks. J Ornithol. 2009:150:183-93.

51. Lensink CJ. Neckbands as an inhibitor of reproduction in black brant. J Wildl Manag. 1968:32:418-20.

52. Lewis TL, Flint PL. Modified method for external attachment of transmitters to birds using two subcutaneous anchors. J Field Ornithol. 2008;79:336-41.

53. Madsen J. Spring migration strategies in Pink-footed Geese Anser brachyrhynchus and consequences for spring fattening and fecundity. Ardea. 2001;89:43-55

54. Montgomery J. A collar radio-transmitter attachment for wood ducks and other avian species. Proc Int Conf Wildl Biotelemetry. 1985;5:19-27.

55. Murray DL, Fuller MR. A critical review of the effects of marking on the biology of vertebrates. In: Boitani L, \& Fuller TK, editors. Research techniques in animal ecology: controversies and consequences. New York: Columbia University Press; 2000. p. 15-64.

56. Nowak E, Berthold P, Querner U. Satellite tracking of migrating Bewick's Swans. Naturwissenschaften. 1990;77:549-50.

57. Nuijten RJ, Kölzsch A, van Gils JA, Hoye BJ, Oosterbeek K, de Vries PP, et al. The exception to the rule: retreating ice front makes Bewick's swans Cygnus columbianus bewickii migrate slower in spring than in autumn. J Avian Biol. 2014:45:113-22. 
58. Olsen GH, Dein FJ, Haramis GM, Jorde DG. Implanting radio transmitters in wintering canvasbacks. J Wildl Manag. 1992;56:325-8.

59. Palm EC, Newman SH, Prosser DJ, Xiao X, Ze L, Batbayar N, Balachanran S, Takekawa JY. Mapping migratory flyways in Asia using dynamic Brownian bridge movement models. Mov Ecol. 2015;3:3.

60. Paquette GA, Devries JH, Emery RB, Howerter DW, Joynt BL, Sankowski TP. Effects of transmitters on reproduction and survival of wild mallards. J Wildl Manag. 1997;61:953-61.

61. Pennycuick CJ, Fast PL, Ballerstadt N, Rattenborg N. The effect of an external transmitter on the drag coefficient of a bird's body, and hence on migration range, and energy reserves after migration. J Ornithol. 2012;153:633-44.

62. Perry MC. Abnormal behavior of canvasbacks equipped with radio transmitters. J Wildl Manag. 1981;45:786-9.

63. Petrie SA, Wilcox KL. Migration chronology of eastern-population tundra swans. Can J Zool. 2003;81:861-70.

64. Phillips RA, Cope DR, Rees EC, O'Connel MJ. Site fidelity and range size of wintering Barnacle Geese Branta leucopsis. Bird Study. 2003;50:161-9.

65. Pietz PJ, Krapu GL, Greenwood RJ, Lokemoen JT. Effects of harness transmitters on behavior and reproduction of wild mallards. J Wildl Manag. 1993;57:696-703.

66. Pietz PJ, Krapu GL, Brandt DA, Cox RR Jr. Factors affecting gadwall brood and duckling survival in prairie pothole landscapes. J Wildl Manag. 2003;67:564-75.

67. Ravelling DG. Social classes of Canada Geese in winter. J Wildl Manag. 1969:33:304-18.

68. Reed ET, Gauthier G, Pradel R. Effects of neck bands on reproduction and survival of female greater snow geese. J Wildl Manag. 2005;69:91-100

69. Reynolds $\mathrm{MH}$. Habitat use and home range of the Laysan Teal on Laysan Island, Hawaii. Waterbirds. 2004;27:183-92.

70. Robert M, Drolet B, Savard JPL. Effects of backpack radio-transmitters on female Barrow's Goldeneyes. Waterbirds. 2006;29:115-20.

71. Rosenberg DH, Pertula MJ, Schamber JL, Zwiefelhofer D, Hollmén TE, Hill DD, Giguère N. Seasonal movements and distribution of Steller's Eiders (Polysticta stelleri) wintering at Kodiak Island, Alaska. Arctic. 2014;67:347-59.

72. Roshier DA, Amus MW. Use of satellite telemetry on small-bodied waterfowl in Australia. Mar Freshw Res. 2009;60:299-305.

73. Rotella JJ, Howerter DW, Sankowski TP, Devries JH. Nesting effort by wild mallards with 3 types of radio transmitters. J Wildl Manag. 1993:57:690-5.
74. Ryan DC, Kawula RJ, Gates RJ. Breeding biology of wood ducks using natural cavities in southern Illinois. J Wildl Manag. 1998;62:112-23.

75. Schmutz JA, Morse JA. Effects of neck collars and radiotransmitters on survival and reproduction of emperor geese. J Wildl Manag. 2000;64:231-7.

76. Sedinger JS, White RG, Hauer WE. Effects of carrying radio transmitters on energy expenditure of Pacific black brant. J Wild Manag. 1990;54:42-5.

77. Sexson MG, Mulcahy DM, Spriggs M, Myers GE. Factors influencing immediate post-release survival of spectacled eiders following surgical implantation of transmitters with percutaneous antennae. J Wildl Manag. 2014:78:550-60.

78. Sheaffer SE, Malecki RA, Swift BL, Dunn J, Scribner K. Management implications of molt migration by the Atlantic flyway resident population of Canada geese, Branta canadensis. Can Field Nat. 2007;121:313-20.

79. Sorensen MD. Effects of neck collar radios on female redheads. J Field Ornithol. 1989:60:523-8.

80. Stahl J, Bos D, Loonen MJJE. Foraging along a salinity gradient: the effect of tidal inundation on site choice by dark-bellied brent geese Branta bernicla and barnacle geese B. leucopsis. Ardea. 2002;90:201-12.

81. Strikwerda TE, Fuller MR, Seegar WS, Howay PW, Black HD. Bird-borne satellite transmitter and location program. Johns Hopkins APL Tech Dig. 1986;7:203-8.

82. Vandenabeele SP, Wilson RP, Grogan A. Tags on seabirds: How seriously are instrument-induced behaviours considered? Animal Welfare. UFAW J. 2011;20:559.

83. Ward DH, Flint PL. Effects of harness-attached transmitters on premigration and reproduction of brant. J Wildl Manag. 1995;59:39-46.

84. White CR, Cassey P, Schimpf NG, Halsey LG, Green JA, Portugal SJ. Implantation reduces the negative effects of bio-logging devices on birds. J Exp Biol. 2013;216:537-42.

85. Wikelski M, Kays R. Movebank: archive, analysis and sharing of animal movement data. Hosted by the Max Planck Institute for Ornithology. 2016. www.movebank.org. Accessed 29 July 2016

86. Wilson RP, McMahon CR. Measuring devices on wild animals: what constitutes acceptable practice? Front Ecol Environ. 2006;4:147-54.

87. Zicus MC, Schultz DF, Cooper JA. Canada goose mortality from neckband icing. Wildl Soc Bull. 1983;11:286-90.

88. Zimmer JM Poor retention rates of 8-g anchor radio transmitters by Northern Shovelers.J Field Ornithol. 1997;86(4): 526-9.

\section{Submit your next manuscript to BioMed Central and we will help you at every step:}

- We accept pre-submission inquiries

- Our selector tool helps you to find the most relevant journal

- We provide round the clock customer support

- Convenient online submission

- Thorough peer review

- Inclusion in PubMed and all major indexing services

- Maximum visibility for your research

Submit your manuscript at www.biomedcentral.com/submit
BioMed Central 